\title{
Sampling bivalves on tidal flats: possibility of missing rare species, versus smoothing of environmental variation
}

\author{
Tanya J. Compton ${ }^{1,2, *}$, Casper Kraan ${ }^{3}$, Micha J. A. Rijkenberg ${ }^{2}$, Tineke A. Troost ${ }^{4}$, \\ Danny I. Rogers ${ }^{5}$, Jutta Leyrer ${ }^{6}$, Grant Pearson ${ }^{7}$, Theunis Piersma ${ }^{2,8}$ \\ ${ }^{1}$ National Institute of Water and Atmospheric Research (NIWA), PO Box 1115, Hillcrest, Hamilton 3216, New Zealand \\ ${ }^{2}$ Royal Netherlands Institute of Sea Research (NIOZ), PO Box 59, 1790 AB Den Burg, Texel, The Netherlands \\ ${ }^{3}$ Department of Computational Landscape Ecology, UFZ Centre for Environmental Research, Permoserstr. 15, 04318 Leipzig, \\ Germany \\ ${ }^{4}$ Deltares, PO Box 177, 2600 MH Delft, The Netherlands \\ ${ }^{5}$ Arthur Rylah Institute for Environmental Research, Department of Sustainability and Environment, 123 Brown Street, \\ PO Box 137, Heidelberg, Victoria 3084, Australia \\ ${ }^{6}$ Centre for Integrative Ecology, School of Life \& Environmental Sciences, Deakin University, Locked Bag 20000, Geelong, \\ Victoria 3220, Australia \\ ${ }^{7}$ Bishop Street, Jolimont, Western Australia 6014,Australia \\ ${ }^{8}$ Animal Ecology Group, Centre for Ecological and Evolutionary Studies, University of Groningen, PO Box 11103 \\ 9700 CC Groningen, The Netherlands
}

\begin{abstract}
Beukema \& Dekker (2011; Mar Ecol Prog Ser 440:281-283) argue that the main conclusion of Compton et al. (2008; Mar Ecol Prog Ser 373:25-35), namely that diversity of bivalve and other benthic organisms on tidal flats is not associated with sediment heterogeneity, is invalid because $\gamma$-diversity was not examined. Our conclusion was, however, based on $\gamma$-diversity. Beukema \& Dekker (2011) also argue that our finding that bivalve point diversity was highest in 'complex' fine-grained sediments is incorrect, because small sampling areas underestimate rare species. Using larger sampling areas would have increased the probability of including rare species, but would also have smoothed away biological and environmental heterogeneity. We used many estimates of point diversity to show that bivalve diversity at a sampling point was higher in finer versus sandier sediments across 9 mudflats and we did not make assumptions about the homogeneity of habitat types. The suggestion that samples should be aggregated on the basis of similar environmental attributes across an area as large as the Wadden Sea would also lead to an under- or overestimation of species diversity because - although sampling locations may share the same sediment characteristics - species composition within a sample will differ due to historical, physical and biological effects.
\end{abstract}

KEY WORDS: Species diversity $\cdot$ Sample area $\cdot$ Sediment $\cdot$ Bivalves

\section{LARGER SAMPLES, AND SAMPLE AGGREGATION}

Compton et al. (2008; Mar Ecol Prog Ser 373: 25-35) concluded that neither bivalve diversity nor total benthic diversity were associated with system sediment heterogeneity across 9 tropical and temp- erate tidal flat systems. In addition, we showed that bivalve diversity within a sample point was highest in 'complex' fine-grained sediments across all 9 systems.

Beukema \& Dekker (2011, this volume) challenge our main conclusion that there is no association 
between system sediment heterogeneity and diversity, and suggested that the conclusion would change if we were to examine $\gamma$-diversity. However, our main conclusion was based on a correlation between total system bivalve and benthic $\gamma$-diversity versus the range in sediment grain sizes for each system. The estimates of $\gamma$-diversity were determined using species accumulation curves for the whole system (see Compton et al. 2008, their 'Materials and methods'). Our conclusion was also supported by boxplots of the raw data, which showed that the individual species overlapped in their distribution, with respect to median grain size, when comparing the different tidal flat systems (see boxplots in Compton et al. 2008, their Fig. 5).

Beukema \& Dekker (2011) also argue against our finding that 'bivalve diversity within a sample point was highest in 'complex' fine-grained sediments' (Compton et al. 2008, p. 25), because our estimates of point diversity $\left(0.02 \mathrm{~m}^{2}\right)$ were too small to encounter the rare species within the community. We agree that larger sample surfaces would yield a greater probability of capturing rare species per sample. However, although sampling a larger area would increase our estimate of point diversity, it would also have smoothed out the natural heterogeneity in the physical and biological environment. Beukema \& Dekker (2011) further state that, instead of having many small estimates of point diversity, we should have aggregated samples that share similar environmental attributes, e.g. sand versus mud, to provide estimates of diversity. However, aggregating samples based solely on sediment composition across an area as large as the Wadden Sea $\left(270 \mathrm{~km}^{2}\right)$ would have smoothed away meaningful variation in the data. Although aggregated samples may share the same sediment median grain size (MGS), these aggregated samples can differ in other attributes that could in turn affect sample point diversity, e.g. other historical, physical or biological factors. Thus, it is difficult to determine when environmental characteristics are similar enough to allow sample aggregation without resulting in under- or overestimation of species diversity. Our statistical regressions did not make assumptions about the homogeneity of habitat types and thus used many estimates of point diversity to show that bivalve diversity within a sample point was higher in finer versus sandier sediments across 9 mudflats (Compton et al. 2008).

Finally, although the Balgzand data-set, upon which the arguments of Beukema \& Dekker (2011) are based, represent a unique collection, the spatial extent of the sampling is limited by comparison
(Beukema et al. 1983, Beukema \& Cadée 1997) with the spatial distribution of samples in Compton et al. (2008). Therefore, it is uncertain if the results from the Balgzand (Beukema \& Dekker 2011) would be representative of the whole western Dutch Wadden Sea as shown in Compton et al. (2008). Furthermore, the distribution of macrozoobenthic species is generally aggregated, i.e. not random, across the Balgzand area (Beukema et al. 1983). As a consequence, the transect sampling across the Balgzand may miss some species, whereas sampling by Compton et al. (2008) covered the entire intertidal area of the Dutch Wadden Sea (see species accumulation curves in Compton et al. 2008, their Fig. 1).

\section{CHANGES IN COMMUNITY COMPOSITION}

Beukema \& Dekker (2011, p. 281) argue that our 'samples were too small, when used on their own, to yield realistic estimates of macrozoobenthic diversity'. They make this argument based on the observation, from their own data, that small sample areas appear to underestimate species in the benthic community. However, if one is interested in examining the distribution of rare species in the benthic community, with respect to environment, we would argue that one could use other approaches, which do not involve smoothing out the natural variation in one's data. One could examine the rate of change in $\beta$ diversity, i.e. species composition, across an environmental gradient. For example, muddy sediments may have high point diversity but may not vary much in species composition from point to point, while sandy sediments may show greater variability in species composition from point to point, i.e. a high turnover in $\beta$-diversity. Aggregating samples would miss this variability. Here, we examine the turnover in bivalve $\beta$-diversity across 3 environmental gradients using Generalized Dissimilarity Modelling (GDM, Ferrier et al. 2007) to examine whether there are more unique species in sandy sediments. The Wadden Sea data set used here is the same as that used by Compton et al. (2008), except that here we use bivalve abundance data instead of presence/ absence. GDM is an extension of matrix regression, which uses a novel algorithm to model the rate of change in community composition ( $\beta$-diversity) with respect to environmental gradients (see Ferrier et al. 2007 for a detailed description). Our results showed that changes in transformed $\beta$-diversity (Ferrier et al. 2007) were mainly explained by inundation time (the maximum value represents relative importance of an 

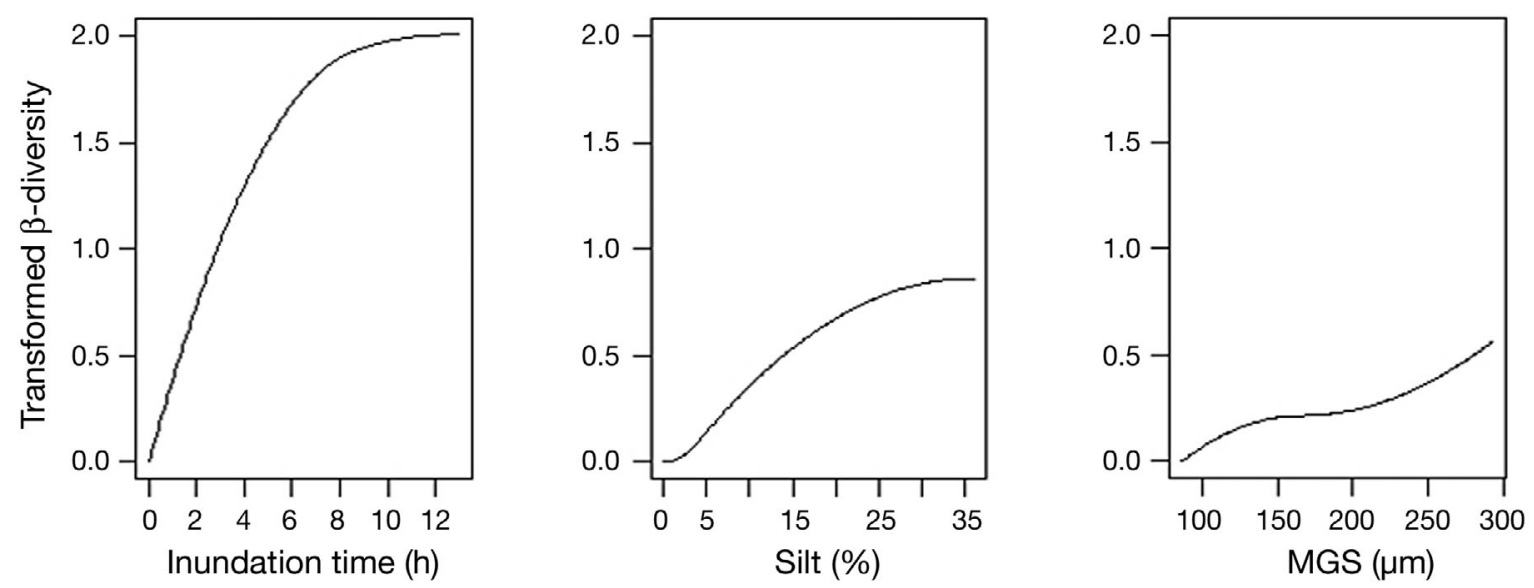

Fig. 1. Fitted curves from a Generalized Dissimilarity model representing the turnover in bivalve $\beta$-diversity along gradients of inundation time, silt and median grain size (MGS). The $y$-axis represents the transformed measure of $\beta$-diversity. The height of the curve indicates the importance of a variable for the turnover in $\beta$-diversity, and the shape of the curve indicates how $\beta$-diversity changes across each environmental gradient.

environmental variable, Fig. 1), followed by silt content and sediment MGS across the Wadden Sea. We also show that changes in transformed $\beta$-diversity were greatest for MGS from 100 to $150 \mu \mathrm{m}$ and then from $\sim 250$ to $300 \mu \mathrm{m}$ (see slopes of the curve for MGS, Fig. 1). Furthermore, the fitted GDM curves showed that changes in $\beta$-diversity were greatest from 0 to $7 \mathrm{~h}$ inundation time and 5 to $25 \%$ silt.

\section{FUTURE DIRECTIONS}

As a final point we would like to add that although previous studies including ours have focussed on sediment as the sole measure of habitat heterogeneity and/or complexity, we believe there have been some interesting steps in the recent literature that further our understanding of the role of habitat complexity for benthic diversity in sedimentary systems (Hewitt et al. 2005, Thrush et al. 2010, de Juan \& Hewitt 2011). For example, de Juan \& Hewitt (2011) showed that habitats with structuring fauna (cockles, seagrass and tubeworms) held higher benthic diversity than purely sedimentary habitats (mud and sand). As benthic organisms can increase the complexity of a habitat (e.g. via sediment reworking) and can also stabilise the seafloor, they can often have positive or negative feedbacks on other species, irrespective of sediment grain size alone. Thus, future work should consider the role of habitat forming species as important drivers of biodiversity within sedimentary systems (Hewitt et al. 2005, Thrush et al. 2006).

\section{CONCLUSIONS}

Although we agree that sampling larger surfaces per sampling point increases the chance of including rare species, large sampling areas are more likely to smooth out the biological and environmental variability among sampling points. In addition, while Beukema \& Dekker (2011) suggested we should use $\gamma$-diversity, our conclusion that bivalve diversity and sediment heterogeneity were not associated across systems was based on $\gamma$-diversity (Compton et al. 2008).

Acknowledgements. Thanks to J. Hewitt and S. Thrush for constructive discussions. Thanks to P. Verburg, I. Rodil and P. Moya for providing useful comments on the manuscript.

\section{LITERATURE CITED}

Beukema JJ, Cadée GC (1997) Local differences in macrozoobenthic response to enhanced food supply caused by mild eutrophication in a Wadden Sea area: food is only locally a limiting factor. Limnol Oceanogr 42:1424-1435

> Beukema JJ, Dekker R (2011) Benthic species diversity and sediment composition: Comment on Compton et al. (2008). Mar Ecol Prog Ser 440:281-283

Beukema JJ, Cadée GC, Hummel H (1983) Differential variability in time and space of numbers in suspension and deposit feeding benthic species in a tidal flat area. Oceanol Acta No Sp:21-26

Compton TJ, Troost TA, van der Meer J, Kraan C and others (2008) Distributional overlap rather than habitat differentiation characterizes co-occurrence of bivalves in intertidal soft sediment systems. Mar Ecol Prog Ser 373:25-35

de Juan S, Hewitt J (2011) Relative importance of local biotic and environmental factors versus regional factors in dri- 
ving macrobenthic species richness in intertidal areas. Mar Ecol Prog Ser 423:117-129

Ferrier S, Manion G, Elith J, Richardson K (2007) Using generalized dissimilarity modelling to analyse and predict patterns of $\beta$ diversity in regional biodiversity assessment. Divers Distrib 13:252-264

> Hewitt JE, Thrush SE, Halliday J, Duffy C (2005) The importance of small-scale habitat structure for maintaining $\beta$ diversity. Ecology 86:1619-1626

Editorial responsibility: Matthias Seaman, Oldendorf/Luhe, Germany
Thrush SF, Hewitt JE, Gibbs M, Lundquist C, Norkko A (2006) Functional role of large organisms in intertidal communities: community effects and ecosystem function. Ecosystems 9:1029-1040

Thrush SF, Hewitt JE, Cummings VJ, Norkko A, Chiantore $M(2010) \beta$-diversity and species accumulation in Antarctic coastal benthos: influence of habitat, distance and productivity on ecological connectivity. PLoS ONE 5: e11899

Submitted: September 7, 2011; Accepted: October 2, 2011 Proofs received from author(s): October 10, 2011 